Prepared for the U.S. Department of Energy

under Contract DE-AC05-76RL01830

\title{
Thermal Wadis in Support of Lunar Exploration: Concept Development and Utilization
}

\author{
J Matyáš \\ JM Burgess \\ RS Wegeng
}

October 2009

\section{Pacific Northwest}

NATIONAL LABORATORY

Proudly Operated by Battelle Since 1965 


\section{Thermal Wadis in Support of Lunar Exploration: Concept Development and Utilization}

J Matyáš

RS Wegeng

October 2009

Prepared for

the U.S. Department of Energy

under Contract DE-AC05-76RL01830

Pacific Northwest National Laboratory

Richland, Washington 99352 



\section{Summary}

Thermal wadis, engineered sources of heat, can be used to extend the life of lunar rovers by keeping them warm during the extreme cold of the lunar night. Thermal wadis can be manufactured by sintering or melting lunar regolith into a solid mass with more than two orders of magnitude higher thermal diffusivities compared to native regolith dust. Small simulant samples were sintered and melted in the electrical furnaces at different temperatures, different heating and cooling rates, various soaking times, under air, or in an argon atmosphere. The samples were analyzed with scanning electron microscopy and energy dispersive spectroscopy, X-ray diffraction, a laser-flash thermal diffusivity system, and the millimeter-wave system. The melting temperature of JSC-1AF simulant was $\sim 50^{\circ} \mathrm{C}$ lower in an argon atmosphere compared to an air atmosphere. The flow of argon during sintering and melting resulted in a small mass loss of 0.04 to $0.1 \mathrm{wt} \%$ because of the volatization of alkali compounds. In contrast, the samples that were heat-treated under an air atmosphere gained from 0.012 to $0.31 \mathrm{wt} \%$ of the total weight. A significantly higher number of cavities were formed inside the samples melted under an argon atmosphere, possibly because of the evolution of oxygen bubbles from iron redox reactions. The calculated emissivity of JSCf-1AF simulant did not change much with temperature, varying between 0.8 and 0.95 at temperatures from 100 to $1200^{\circ} \mathrm{C}$. The thermal diffusivities of raw regolith that was compressed under a pressure of 9 metric tons ranged from 0.0013 to 00011 in the 27 to $390^{\circ} \mathrm{C}$ temperature range. The thermal diffusivities of sintered and melted JSC-1AF simulant varied from 0.0028 to $0.0072 \mathrm{~cm}^{2} / \mathrm{s}$ with the maximum thermal diffusivities observed in the samples that were heated up $5^{\circ} \mathrm{C} / \mathrm{min}$ from room temperature to $1150^{\circ} \mathrm{C}$ under argon or air. These thermal diffusivities are high enough for the rovers to survive the extreme cold of the Moon at the rim of the Shackleton Crater and allow them to operate for months (or years) as opposed to weeks on the lunar surface. Future investigations will be focused on a system that can efficiently construct a thermal wadi from the lunar mare regolith. Solar heating, microwave heating, or electrical resistance melting are considered. 



\section{Acronyms}

$\begin{array}{ll}\text { EDS } & \text { energy dispersive spectroscopy } \\ \text { JSC } & \text { Johnson Space Center } \\ \text { LFTD } & \text { laser-flash thermal diffusivity } \\ \text { MMW } & \text { millimeter wave } \\ \text { MW } & \text { millimeter-wave } \\ \text { NASA } & \text { National Aeronautics and Space Administration } \\ \text { RT } & \text { room temperature } \\ \text { SEM } & \text { scanning electron microscopy } \\ \text { XRD } & \text { X-ray diffraction }\end{array}$





\section{Acknowledgments}

Jeremy Burgess is grateful to the U.S. Department of Energy Community College Institute of Science and Technology Program for the fellowship appointment at Pacific Northwest National Laboratory, which is operated for the U.S. Department of Energy by Battelle under Contract DE-AC05-76RL01830. The authors gratefully acknowledge Nantel Suzuki from NASA for providing funding for this project and Dr. Allen Wilkinson from the NASA Glenn Research Center for supplying JSC-1AF simulant. 



\section{Contents}

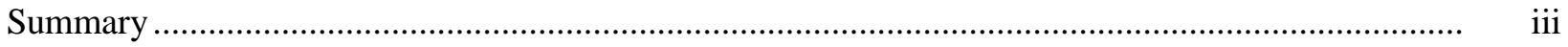

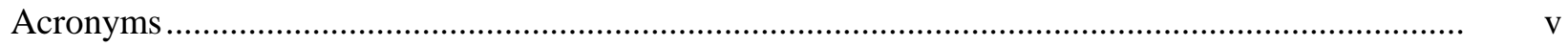

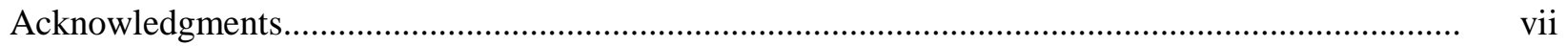

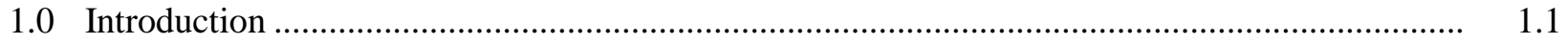

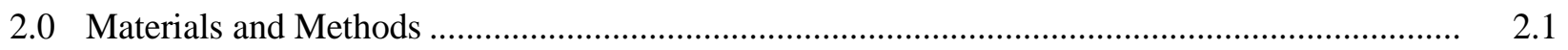

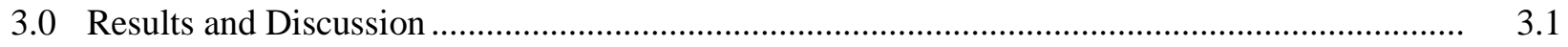

3.1 Heat-Treatments Under Air Atmosphere …........................................................................ 3.1

3.2 Heat-Treatments Under Argon Atmosphere ............................................................... 3.2

3.3 Thermal Diffusivity Measurements.................................................................................... 3.4

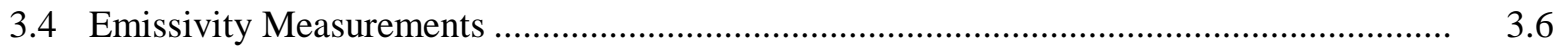

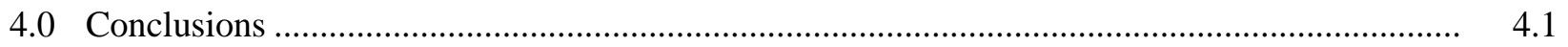

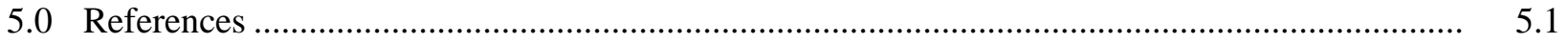

\section{Figures}

3.1. SEM Images of Sintered JSC-1AF Simulant....................................................................

3.2. XRD Pattern of Sintered JSC-1AF Simulant ..........................................................................

3.3. SEM Images of Melted JSC-1AF Simulant ...................................................................................

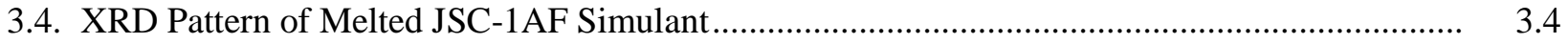

3.5. Calculated Emissivity of Regolith Simulant JSC-1A as a Function of Temperature .................. 3.7

\section{Tables}

2.1. Composition of JSC-1AF Simulant in wt\% of Oxides .............................................................. 2.1

3.1. EDS Analysis of Crystalline Phases in the Quenched JSC-1AF Simulant ................................. 3.2

3.2. EDS Analysis of Crystalline Phases in the Quenched JSC-1AF Simulant................................ 3.3

3.3. Thermal Diffusivities of Analyzed Samples ............................................................................... 



\subsection{Introduction}

The National Aeronautics and Space Administration (NASA) plans to return to the Moon no later than 2020. However, the extreme cost of exploring the Moon has always been an issue for NASA. Between 1961 and 1972, the Apollo program required \$25 billion (Lowman 2007), which would be approximately $\$ 128$ billion in 2009 dollars (Williamson 2008). This expenditure has prompted studies to determine the most cost-efficient plan for a return to the Moon. One of the areas where cost effectiveness could be improved is with the use of lunar rovers. Electronic devices, in general, will cease to function at temperatures below $-55^{\circ} \mathrm{C}$ (Ghaffarian 2002), which is problematic because temperatures on the Moon during the lunar night can drop to about $-173^{\circ} \mathrm{C}$ (Balasubramaniam et al. 2009). One of the most promising locations of a lunar station would be at the south pole of the moon where the amount of time in sunlight would be maximized (Dale 2006). This would diminish the amount of time that the rovers must spend in the lunar darkness, which is currently estimated at 52 Earth-hours at Shackleton Crater rim (Balasubramaniam et al 2009).

An alternative to having these lunar rovers expire when the lunar night sets in is to furnish a heat source to the rovers so the rovers can be stored and remain warm during the lunar night. Then they could be put back into service when it is once again lunar daytime. Material can be transferred to the lunar surface from Earth to provide this heat source at a cost of \$50 000 to \$100 000 per kilogram (Wegeng et al. 2008). As an alternative, the lunar regolith can be thermally processed to manufacture a thermal mass material with improved thermal properties that will keep the lunar rovers warm.

Lunar regolith can be converted into a thermal wadi, which is an engineered source of heat (Wegeng et al. 2008), using a variety of processes, including sintering and melting with microwave, solar, and electrical resistance heating. The thermal wadis could then be used on the lunar surface to set up a network of outposts where the lunar rovers could remain warm during periods of lunar darkness. This network would allow more efficient and effective exploration of the moon by dramatically increasing the surface area of the moon that can be explored. The extended range of coverage will provide information about the early history of the Moon as well as the structure of the lunar crust.

Since the Apollo missions collected a limited amount of lunar regolith, researchers at the Johnson Space Center (JSC) have prepared a simulant JSC-1A from a volcanic ash deposit located in the San Francisco volcano field near Flagstaff, Arizona, which exhibits similar properties to the lunar regolith. This simulant was used to study the effect of experimental conditions (e.g., T, t, and atmosphere) on sintering and melting of lunar regolith and to identify the optimal process of manufacturing the thermal mass material. The sintering and melting of small simulant samples was performed in the electrical furnaces at different temperatures, different heating and cooling rates, various soaking times, under air, or in an argon atmosphere. The samples were analyzed with scanning electron microscopy and energy dispersive spectroscopy (SEM-EDS), X-ray diffraction (XRD), a laser-flash thermal diffusivity (LFTD) system, and the millimeter-wave (MW) system. 



\subsection{Materials and Methods}

Table 2.1 summarizes the composition of lunar mare regolith simulant JSC-1AF in wt\% of oxides. The initial sintering and melting experiments were conducted under air atmosphere in the electrical furnaces. Approximately $15 \mathrm{~g}$ of JSC-1AF simulant powder was transferred into square platinum crucibles $(2.50 \times 2.50 \mathrm{~cm})$ of $2.20 \mathrm{~cm}$ height. The first set of samples was put in the furnace at selected temperatures ranging from 850 to $1200^{\circ} \mathrm{C}$ and removed after 1 or 16 hours. Another set of samples was heated up $5^{\circ} \mathrm{C} / \mathrm{min}$ from room temperature (RT) to target temperatures from 1000 to $1200^{\circ} \mathrm{C}$ and quenched. One sample was heated up $5^{\circ} \mathrm{C} / \mathrm{min}$ from RT to $1150^{\circ} \mathrm{C}$. Then, the sample was allowed to dwell at $1150^{\circ} \mathrm{C}$ for 6 minutes and cooled down at $15^{\circ} \mathrm{C} / \mathrm{h}$ to $\mathrm{RT}$.

To simulate the atmosphere on the Moon, matching experiments for successfully sintering or melting samples were run in the mullite tube furnace under an argon atmosphere. The argon flow of $780 \mathrm{~mL} / \mathrm{min}$ was started, the samples were placed into the furnace, and then the heating commenced.

Processed samples were cut in half diagonally using a low-speed diamond saw. The first half of each sample was polished using 240-, 600-, and 1200-grit paper. The samples were mounted onto a microscopic slide and cut again to prepare the thin sections. The top faces of the mounted samples were polished using the above-mentioned grit paper. The final polishing was accomplished with a 3- $\mu$ m, $1-\mu \mathrm{m}$, and $0.25-\mu \mathrm{m}$ diamond suspension solution. The sample thin sections were analyzed for crystalline phases with an optical microscope and SEM-EDS.

The second half of each sample was used to make 1.5-cm-thick disks of $1 \mathrm{~cm}$ in diameter. The samples were mounted onto an alumina plate with high-temperature glue, core drilled, and core sample cross-sectioned. In addition, a disk of the same size and thickness was produced from regolith by pressing $\sim 0.15 \mathrm{~g}$ of raw regolith simulant at room temperature under a pressure of 9 metric tons. The disks of different samples were tested with LFTD to determine their thermal diffusivities.

The residual material from cutting was ground in a tungsten carbide mill for 2 minutes. The powdered samples were mixed with $\sim 5 \mathrm{wt} \%$ of $\mathrm{CaF}_{2}$ in a tungsten carbide mill for 1 minute and analyzed with XRD to identify the crystalline phases.

Approximately $750 \mathrm{~g}$ of regolith stimulant was transferred into a 600-mL Pt-crucible, heated up in air at $5^{\circ} \mathrm{C} / \mathrm{min}$ from $100^{\circ} \mathrm{C}$ to $1200^{\circ} \mathrm{C}$, and evaluated with the millimeter wave (MMW) system to determine the emissivity of JSC-1AF as a function of temperature.

Table 2.1. Composition of JSC-1AF Simulant in wt\% of Oxides

\begin{tabular}{cccccccccccc}
\hline Component & $\mathrm{Al}_{2} \mathrm{O}_{3}$ & $\mathrm{CaO}$ & $\mathrm{Fe}_{2} \mathrm{O}_{3}$ & $\mathrm{FeO}$ & $\mathrm{K}_{2} \mathrm{O}$ & $\mathrm{MgO}$ & $\mathrm{Na}_{2} \mathrm{O}$ & $\mathrm{P}_{2} \mathrm{O}_{5}$ & $\mathrm{SiO}_{2}$ & $\mathrm{TiO}_{2}$ & $\mathrm{MnO}$ \\
\hline Wt \% & 17.1 & 10.3 & 3.41 & 7.57 & 0.86 & 6.9 & 3.3 & 0.76 & 47.1 & 1.87 & 0.18 \\
\hline
\end{tabular}





\subsection{Results and Discussion}

\subsection{Heat-Treatments Under Air Atmosphere}

The samples of JSC-1AF simulant that were heat-treated at temperatures from $850^{\circ} \mathrm{C}$ to $1050^{\circ} \mathrm{C}$ for 1 hour showed minor sintering shrinkage and were still present in the powder form. In contrast, the brown sintered bricks were formed at $1100^{\circ} \mathrm{C}$ and $1125^{\circ} \mathrm{C}$ with the $1125^{\circ} \mathrm{C}$ sample exhibiting a slightly darker shade of brown than the $1100^{\circ} \mathrm{C}$ sample. An extensive cracking horizontally along the sides of the brick was observed at $1125^{\circ} \mathrm{C}$. A deep-brown sintered brick resulted from heat-treatment at $1100^{\circ} \mathrm{C}$ with a soak time of 16 hours. The simulant turned into a black glass after heat-treatment at $1150^{\circ} \mathrm{C}$ and $1200^{\circ} \mathrm{C}$ with a soak time of 1 hour, and at $1150^{\circ} \mathrm{C}$ with a soak time of 16 hours. Interestingly, all the samples that were heat-treated under air atmosphere at different temperatures for 1 hour gained weight, ranging from 0.012 to $0.31 \mathrm{wt} \%$ of the total weight.

Minor sintering that was unable to hold the simulant powder together occurred in the samples that were heated up $5^{\circ} \mathrm{C} / \mathrm{min}$ from RT to $1000^{\circ} \mathrm{C}, 1050^{\circ} \mathrm{C}$, and $1100^{\circ} \mathrm{C}$. A sample of simulant that was heattreated under the same conditions but removed at $1150^{\circ} \mathrm{C}$ was converted into a sintered brick. The SEM images of this sample detailing the sintered grains of JSC-1AF simulant and newly formed crystalline phases are shown in Figure 3.1. The compositions of newly formed crystalline phases as determined with EDS are shown in Table 3.1. Three distinct phases were identified. The dark grey phase seemed to be a calcium aluminum silicate with trace amounts of magnesium, potassium, and iron. The composition of the light gray phase indicated the presence of a magnesium-iron-calcium-aluminum-silicate phase with trace amounts of sodium and titanium. The major components of white crystals were iron and titanium. The XRD analysis identified three crystalline phases: anorthite, diopside, and hematite (Figure 3.2).
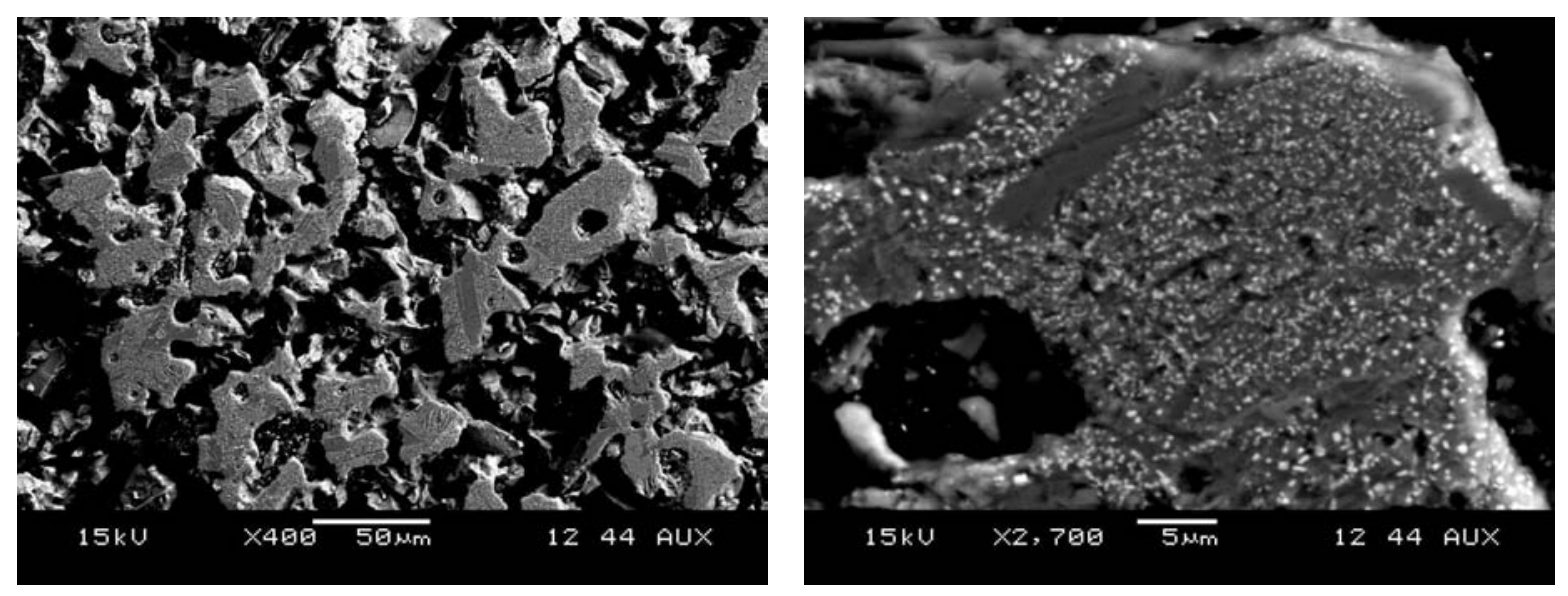

Figure 3.1. SEM Images of Sintered JSC-1AF Simulant. The simulant was heated up $5^{\circ} \mathrm{C} / \mathrm{min}$ from room temperature (RT) to $1150^{\circ} \mathrm{C}$ under an air atmosphere. 
Table 3.1. EDS Analysis of Crystalline Phases in the Quenched JSC-1AF Simulant. The simulant was heated up $5^{\circ} \mathrm{C} / \mathrm{min}$ from $\mathrm{RT}$ to $1150^{\circ} \mathrm{C}$ under an air atmosphere.

\begin{tabular}{crrrrrrrrr}
\hline \multirow{2}{*}{ Phases } & \multicolumn{10}{c}{ Element, wt\% } \\
\cline { 2 - 10 } & \multicolumn{1}{c}{$\mathrm{O}$} & $\mathrm{Na}$ & \multicolumn{1}{c}{$\mathrm{Mg}$} & \multicolumn{1}{c}{$\mathrm{Al}$} & \multicolumn{1}{c}{$\mathrm{Si}$} & \multicolumn{1}{c}{$\mathrm{K}$} & $\mathrm{Ca}$ & $\mathrm{Ti}$ & \multicolumn{1}{c}{$\mathrm{Fe}$} \\
\hline Dark gray & 28.16 & $\mathrm{~N} / \mathrm{A}$ & 0.31 & 21.53 & 35.85 & 0.44 & 12.39 & $\mathrm{~N} / \mathrm{A}$ & 1.32 \\
Light gray & 24.05 & 0.60 & 10.09 & 3.49 & 31.50 & N/A & 18.58 & 1.38 & 10.04 \\
White crystals & 16.83 & N/A & 4.53 & 0.83 & 0.57 & N/A & 0.42 & 9.80 & 67.02 \\
\hline
\end{tabular}

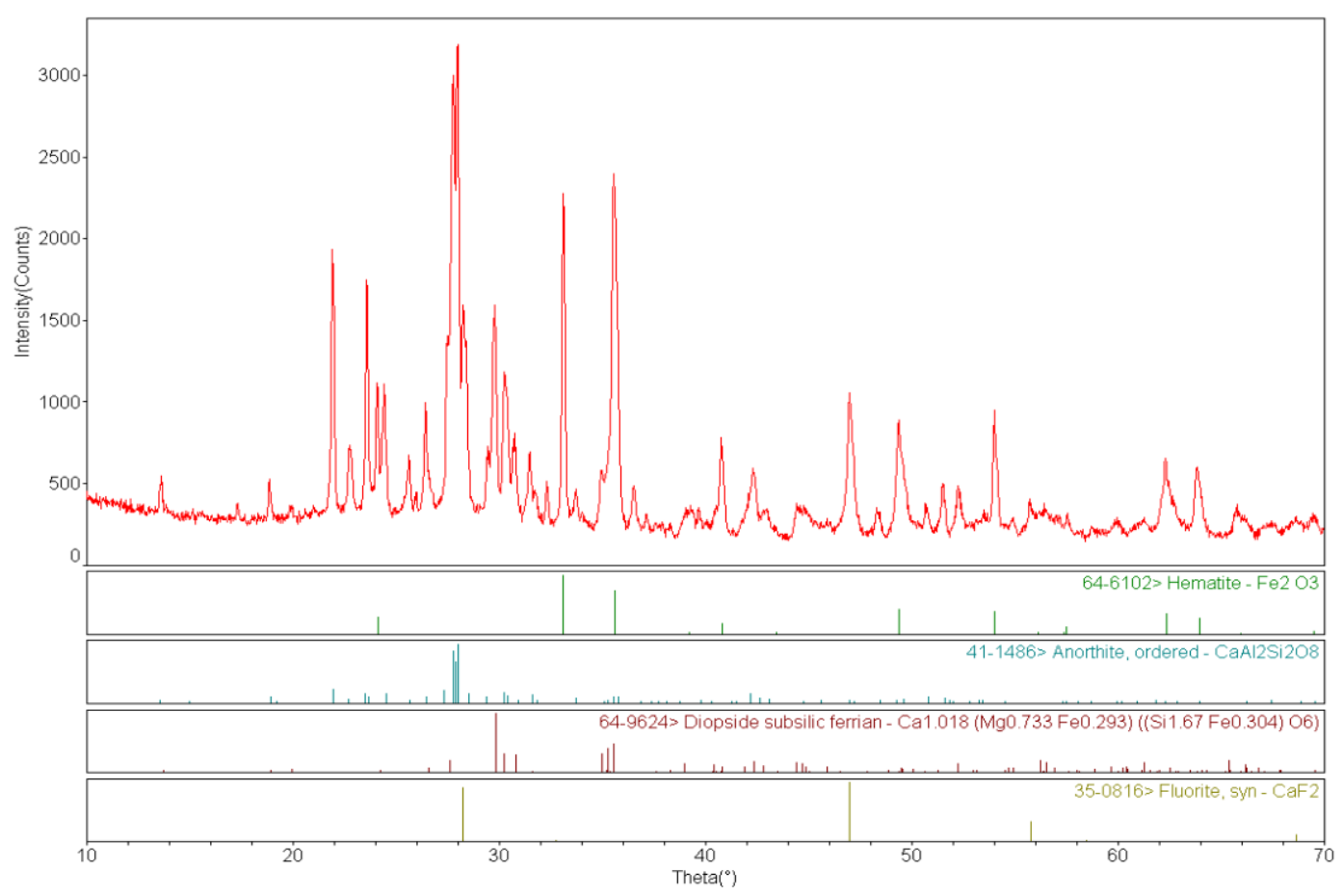

Figure 3.2. XRD Pattern of Sintered JSC-1AF Simulant. The simulant was heated up $5^{\circ} \mathrm{C} / \mathrm{min}$ from RT to $1150^{\circ} \mathrm{C}$ under an air atmosphere.

\subsection{Heat-Treatments Under Argon Atmosphere}

The sample of JSC-1AF simulant that was heat-treated at $1053^{\circ} \mathrm{C}$ for 1 hour sintered into a fragile brown brick. The samples heat-treated at $1101^{\circ} \mathrm{C}$ and $1126^{\circ} \mathrm{C}$ for 1 hour sintered into sturdy brown and black bricks, respectively. The JSC-1AF simulant was converted into black glass during heat-treatments at $1151^{\circ} \mathrm{C}$ and $1204^{\circ} \mathrm{C}$ for 1 hour. In contrast to air atmosphere heat-treatments, the samples that were heat-treated under an argon atmosphere at different temperatures for 1 hour exhibited a mass loss ranging from 0.59 to $0.69 \mathrm{wt} \%$. The samples of simulant that were heat-treated at $5^{\circ} \mathrm{C} / \mathrm{min}$ from $\mathrm{RT}$ to $1100^{\circ} \mathrm{C}$ or $1195^{\circ} \mathrm{C}$ were converted into a sintered brown brick and black glass, respectively. The top center of the sample that was heat-treated under the same conditions but removed at $1150^{\circ} \mathrm{C}$ was sintered, and the rest 
of the sample was melted into a black glass. The SEM images of this sample are shown in Figure 3.3. Three crystalline phases similar to crystalline phases identified in the samples that were heat-treated under the same conditions but air atmosphere have been identified with EDS (Table 3.2). The XRD identified four distinct crystalline phases: hematite, anorthite, diopside, and forsterite (Figure 3.4).
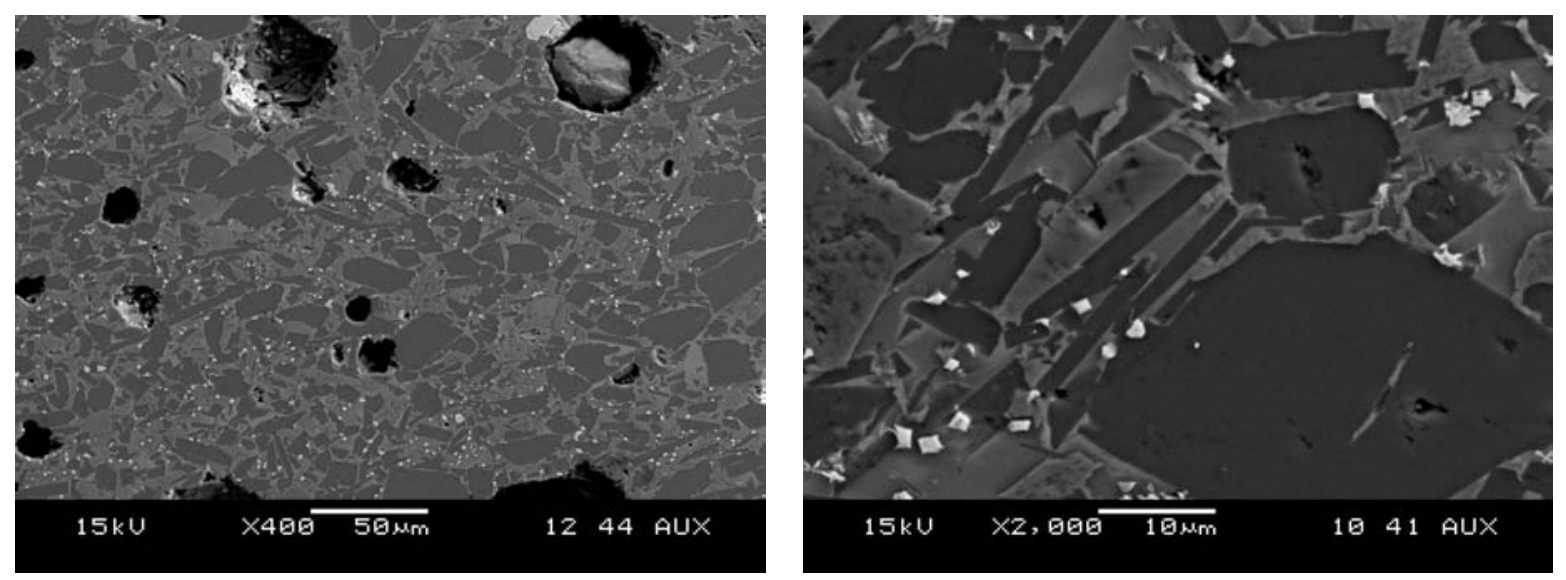

Figure 3.3. SEM Images of Melted JSC-1AF Simulant. The simulant was heated up $5^{\circ} \mathrm{C} / \mathrm{min}$ from RT to $1150^{\circ} \mathrm{C}$ under an argon atmosphere.

Table 3.2. EDS Analysis of Crystalline Phases in the Quenched JSC-1AF Simulant. The simulant was heated up $5^{\circ} \mathrm{C} / \mathrm{min}$ from $\mathrm{RT}$ to $1150^{\circ} \mathrm{C}$ under an argon atmosphere.

\begin{tabular}{ccccccccccc}
\hline \multirow{2}{*}{ Phases } & \multicolumn{10}{c}{ Element, wt\% } \\
\cline { 2 - 10 } & $\mathrm{O}$ & $\mathrm{Na}$ & $\mathrm{Mg}$ & $\mathrm{Al}$ & $\mathrm{P}$ & $\mathrm{Si}$ & $\mathrm{K}$ & $\mathrm{Ca}$ & $\mathrm{Ti}$ & $\mathrm{Fe}$ \\
\hline $\begin{array}{c}\text { Dark } \\
\text { gray }\end{array}$ & 25.89 & 2.12 & $\mathrm{~N} / \mathrm{A}$ & 23.01 & $\mathrm{~N} / \mathrm{A}$ & 33.55 & $\mathrm{~N} / \mathrm{A}$ & 14.39 & $\mathrm{~N} / \mathrm{A}$ & 1.03 \\
$\begin{array}{c}\text { Light } \\
\text { gray }\end{array}$ & 25.69 & 3.00 & 4.39 & 10.83 & 0.53 & 32.13 & 1.47 & 9.69 & 1.84 & 10.42 \\
$\begin{array}{c}\text { White } \\
\text { crystals }\end{array}$ & 14.14 & 0.41 & 3.45 & 3.98 & $\mathrm{~N} / \mathrm{A}$ & 2.21 & 0.3 & 0.63 & 7.34 & 67.54 \\
\hline
\end{tabular}




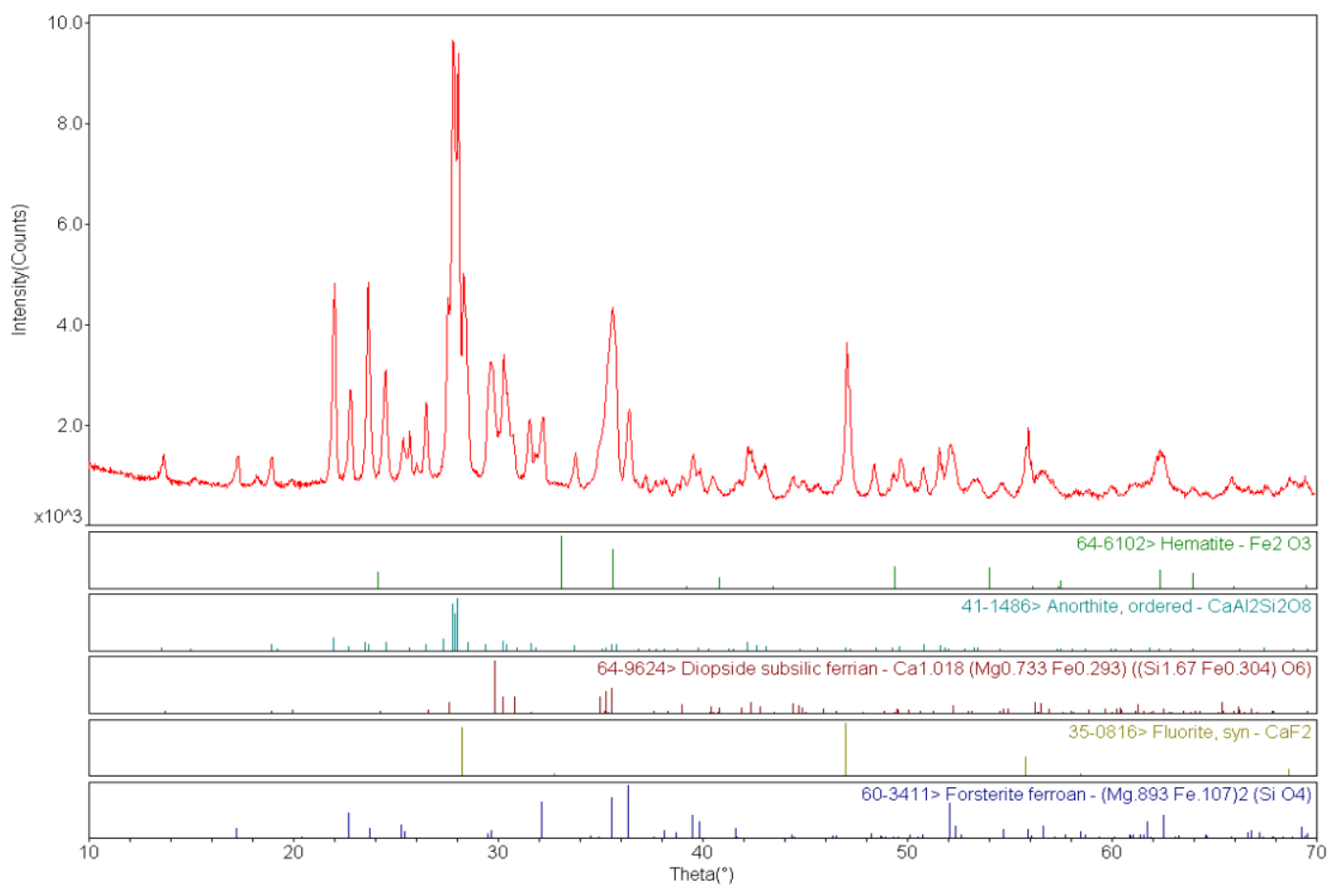

Figure 3.4. XRD Pattern of Melted JSC-1AF Simulant. The simulant was heated up $5^{\circ} \mathrm{C} / \mathrm{min}$ from RT to $1150^{\circ} \mathrm{C}$ under an argon atmosphere.

\subsection{Thermal Diffusivity Measurements}

The front face of small disk-shaped samples ( $\sim 10 \mathrm{~mm}$ in diameter and $\sim 1.5 \mathrm{~mm}$ thick) was subjected to a very short spurt of laser energy. Irradiation times were approximately 1 millisecond or less. The resulting temperature rise of the rear surface of the sample was measured, and thermal diffusivity values were calculated from the time for the back surface to reach $50 \%$ of its maximum temperature. If the thickness of the sample is $\mathrm{L}$ and the $50 \%$ rise time is $t_{1 / 2}$, then the thermal diffusivity is determined as $\alpha=0.1388 * \mathrm{~L}^{2} / \mathrm{t}_{1 / 2}$. Table 3.3 summarizes the obtained thermal diffusivities of different samples. 
Table 3.3. Thermal Diffusivities of Analyzed Samples

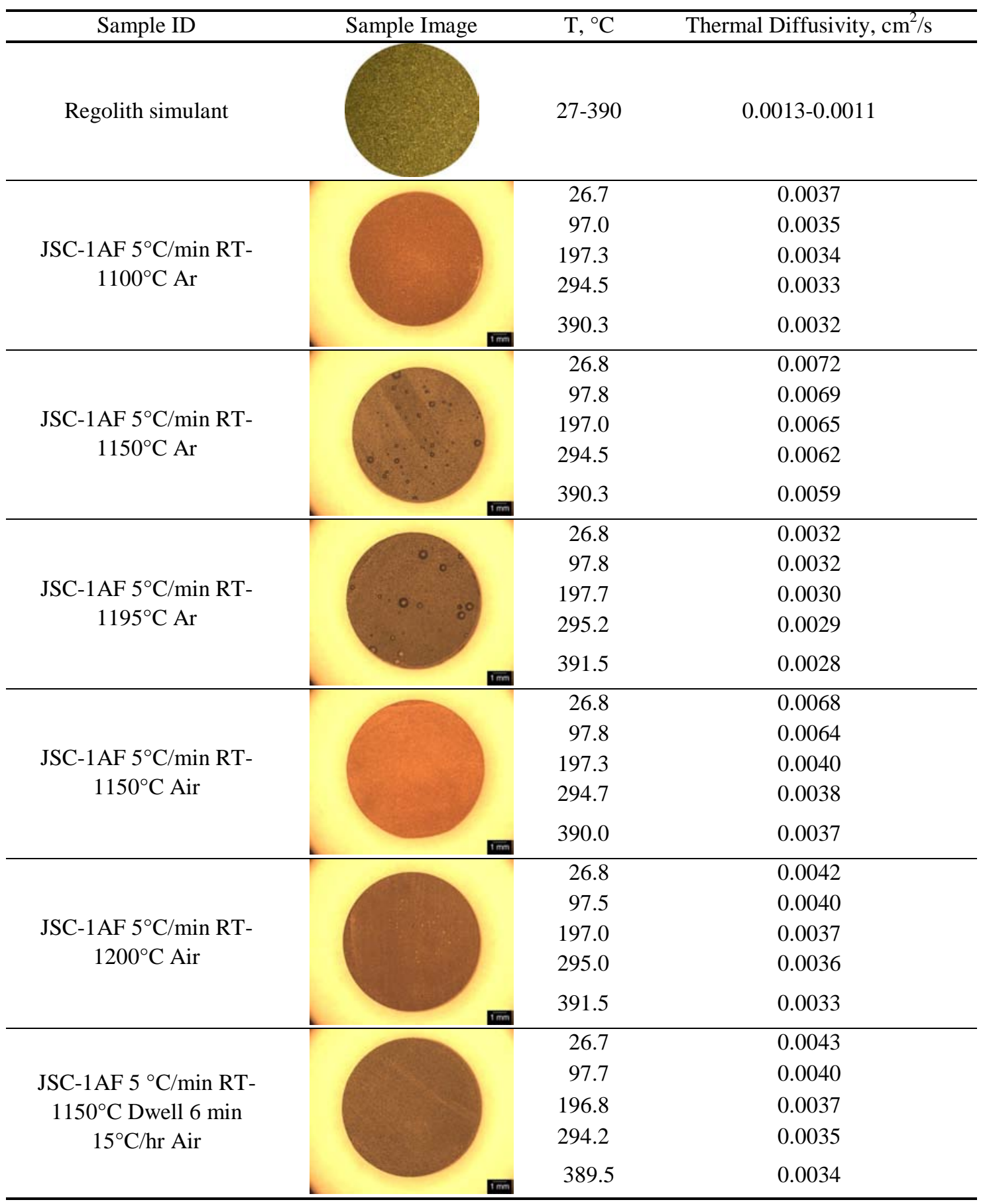




\subsection{Emissivity Measurements}

Approximately $750 \mathrm{~g}$ of regolith stimulant was transferred into a 600-mL Pt-crucible and heated up in air at $5^{\circ} \mathrm{C} / \mathrm{min}$ from $100^{\circ} \mathrm{C}$ to $1200^{\circ} \mathrm{C}$ with a soak time 4 hours. During the test, the sample was monitored with a 137-GHz heterodyne dual-receiver MMW radiometer/interferometer. The receiver receives signals from the sample and transmits a MMW probe signal back to the sample to monitor reflections. The temperature and emissivity of the monitored surface were obtained by measuring the MMW thermal radiation from the surface and using this radiation by the thermal return reflection mirror as a probe of the surface reflectivity (Woskov and Sundaram 2002). The sample temperature and emissivity were calculated using the equations 3.1 through 3.4 .

$$
\begin{gathered}
T_{r_{1}}=\frac{1}{\tau_{c h o p}}\left[\left(\frac{V_{\text {sig, }, 1}}{V_{c a l, 1}}\right) \mid\left(\tau_{c h o p} T_{c a l}-T_{a m b}\right)+T_{a m b}\right] \\
T_{r_{2}}=\frac{V_{s i g, 2}}{V_{c a l, 2}}\left|\left(T_{c a l}-T_{a m b}\right)\right|+T_{a m b} \\
r_{s}=1-\varepsilon_{s}=\frac{1}{\tau_{c h o p}^{2} \tau_{k}\left(\tau_{w g b} \tau_{w g c}\right)^{2} r_{b s}^{2}}\left(1-\frac{T_{r_{2}}}{T_{r_{1}}}\right) \\
T_{S}=\frac{1}{\varepsilon_{s} \tau_{w g b} \tau_{w g c}}\left(T_{r_{2}}-\varepsilon_{w g b} T_{w g b}-\varepsilon_{w g c} T_{w g c} \tau_{w g b}-\varepsilon_{w g c} T_{w g c} r_{s} \tau_{k} \tau_{w g b} \tau_{w g c}-\varepsilon_{w g b} T_{w g b} r_{s} \tau_{k} \tau_{w g b} \tau_{w g c}^{2}\right)
\end{gathered}
$$

where

$$
\begin{aligned}
T_{r_{1}} \text { and } T_{r_{2}} & =\text { radiometric temperatures in } \mathrm{K} \\
\tau_{c h o p} & =\text { chopper wheel transmissivity (0.95) } \\
V_{s i g, 1} \text { and } V_{s i g, 2}= & \text { raw-signal voltages from receivers } \\
T_{c a l} \text { and } T_{a m b}= & \text { calibration and ambient temperatures (77 and 295K) } \\
V_{c a l, 1} \text { and } V_{c a l, 2}= & \text { calibration voltages for liquid nitrogen in aluminum waveguide port } \\
& \left(5.4 \times 10^{-4} \text { and } 4.8 \times 10^{-4}\right) \\
\tau_{k}= & \text { coupling factor between thermal return reflection and sample surface (1) } \\
\tau_{w g b} \text { and } \tau_{w g c}= & \text { transmissivity of the brass and ceramic waveguide sections (0.99 and } 0.85) \\
\varepsilon_{w g b} \text { and } \varepsilon_{w g c}= & \text { emissivity of the brass and ceramic waveguide sections (0.01 and } 0.15) \\
r_{b s}= & \text { reflectivity of the quartz beamsplitter (0.54) } \\
T_{w g b} \text { and } T_{w g c}= & \text { measured thermocouple temperatures of brass and ceramic waveguides in } \mathrm{K} \\
r_{s}= & \text { calculated sample reflectivity } \\
\varepsilon_{s} & =\text { calculated sample emissivity } \\
T_{S} & \text { calculated sample temperature. }
\end{aligned}
$$

Figure 3.5 shows the calculated emissivity of regolith simulant as a function of temperature. 


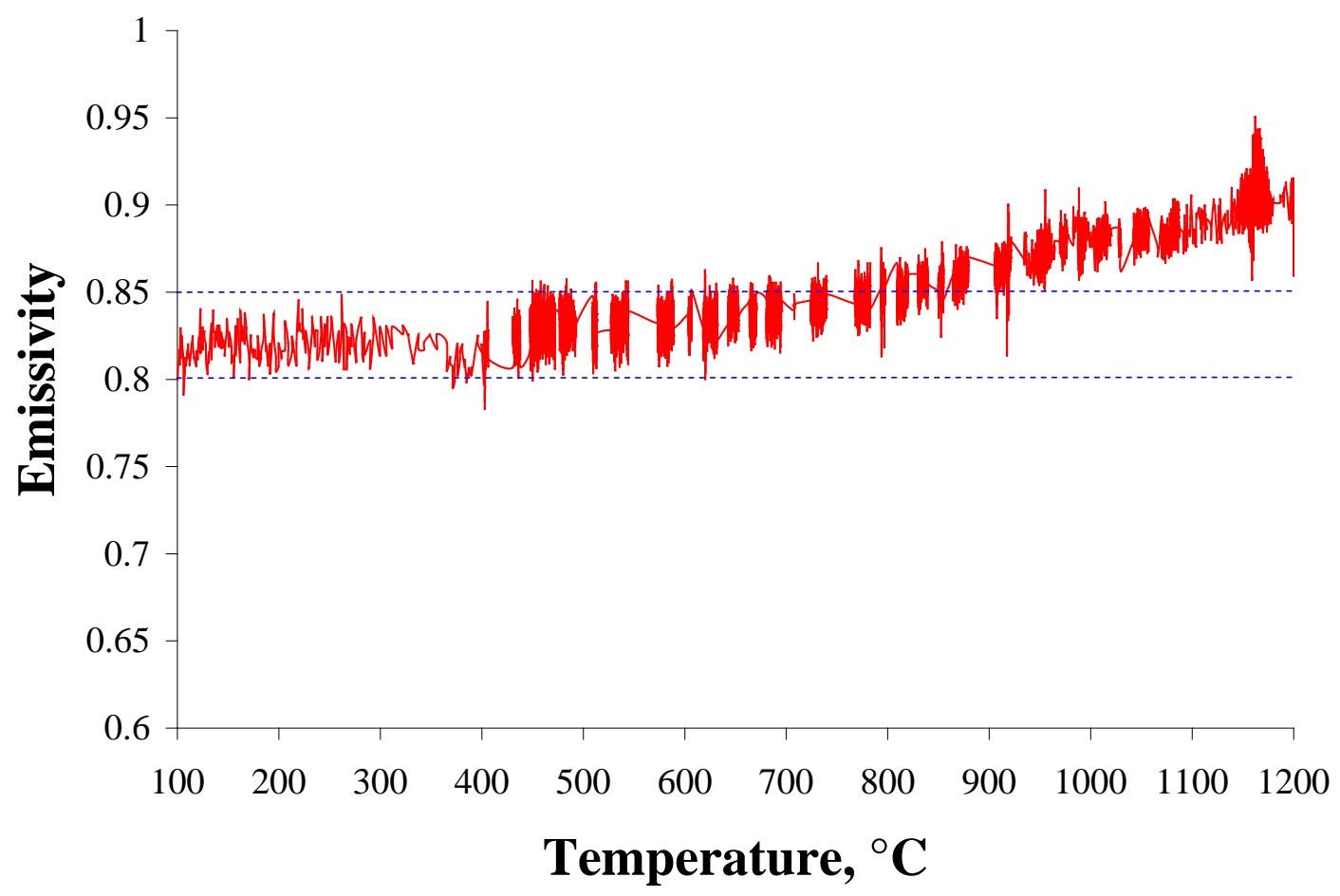

Figure 3.5. Calculated Emissivity of Regolith Simulant JSC-1A as a Function of Temperature 



\subsection{Conclusions}

Compared to an air atmosphere, the argon atmosphere lowered the melting temperature of JSC-1AF simulant by $\sim 50^{\circ} \mathrm{C}$. The SEM images shown in Figure 3.1 and Figure 3.3 detail the distinct differences in the samples that were heat-treated at $5^{\circ} \mathrm{C} / \mathrm{min}$ from RT to $1150^{\circ} \mathrm{C}$ under different atmospheres. The sample heat-treated under air atmosphere was sintered, while the sample heat-treated under argon atmosphere was melted into glass. In addition, the flow of argon during sintering and melting resulted in a small mass loss of 0.04 to $0.1 \mathrm{wt} \%$ because of the volatization of alkali compounds. In contrast, the samples that were heat-treated under air atmosphere gained from 0.012 to $0.31 \mathrm{wt} \%$ of weight.

Furthermore, a significantly higher number of cavities were formed in the samples melted under an argon atmosphere, possibly because of the evolution of oxygen bubbles from iron redox reactions.

The calculated emissivity of JSCf-1AF simulant did not change much with temperature, varying between 0.8 and 0.95 at temperatures from 100 to $1200^{\circ} \mathrm{C}$. The linear increase of emissivity $(0.02$ per $100^{\circ} \mathrm{C}$ ) was observed in the temperature range from 800 to $1200^{\circ} \mathrm{C}$.

The high-emissivity material in combination with an infrared reflecting shield that can be installed above the rover and configured to either reflect solar energy onto the thermal mass during periods of sunlight or reflect infrared energy back to the thermal mass during periods of darkness might be favorable to the thermal wadi concept because it can be rapidly heated up. It also exhibits a uniform temperature distribution.

The thermal diffusivities of raw regolith compressed under a pressure of 9 metric tons ranged from 0.0013 to 00011 in the 27 to $390^{\circ} \mathrm{C}$ temperature range. The thermal diffusivities of sintered and melted JSC-1AF simulant varied from 0.0028 to $0.0072 \mathrm{~cm}^{2} / \mathrm{s}$ with the maximum thermal diffusivities observed in the samples that were heated up $5^{\circ} \mathrm{C} / \mathrm{min}$ from RT to $1150^{\circ} \mathrm{C}$ under argon or $5^{\circ} \mathrm{C} / \mathrm{min}$ from RT to $1150^{\circ} \mathrm{C}$ under air. These thermal diffusivities are about six times higher than raw regolith and high enough for the rovers to survive the extreme cold of the Moon at the rim of Shackleton Crater and allow them to operate for months (or years) as opposed to weeks on the lunar surface. A significant advantage of the concept is the use of modified lunar regolith as the thermal mass material. This will substantially reduce the mass that must be brought from Earth. Future investigations will be focused on a system that can efficiently construct a thermal wadi from the lunar mare regolith. Solar heating, microwave heating, or electrical resistance melting are considered. 



\subsection{References}

Balasubramaniam R, R Wegeng, S Gokoglu, N Suzuki, and K Sacksteder. 2009. “Analysis of SolarHeated Thermal Wadis to Support Extended-Duration Lunar Exploration.” Presented at $47^{\text {th }}$ AIAA Aerospace Sciences Meeting, Including The New Horizons Forum and Aerospace Exposition, Orlando, Florida, January 5-8, 2009.

Dale S. 2006. “Exploration Strategy and Architecture.” NASA, $2^{\text {nd }}$ Space Exploration Conference, Dec. 4, 2006. Available at: http://www.nasa.gov/pdf/163896main_Exploration-LAT_Briefing_120406.pdf. [Accessed: June 18, 2009].

Ghaffarian R. 2002. "NEPP Parts and Packaging Cold Temperature Electronics Task Team Report and Their Findings.” EEE Links 8(2):13-14. Available at:

http://nepp.nasa.gov/eeelinks/August2002/EEELINKS_AUG_2002.PDF. [Accessed June 18, 2009].

Lowman P, Jr. 2007. “Our First Lunar Program: What did we get from Apollo?” NASA, In Their Own Words, Oct. 17, 2007. Available at:

http://www.nasa.gov/centers/goddard/news/series/moon/first lunar_program.htm. [Accessed: June 18, 2009].

Wegeng R, Mankins J., Balasubramaniam, Saksteder K., Gokoglu S. 2008. “Thermal Wadis in Support of Lunar Science and Exploration.” Presented at $6^{\text {th }}$ International Energy Conversion Engineering Conference, Cleveland, Ohio, July 28-30, 2008.

Williamson S. 2008. "Six Ways to Compute the Relative Value of a U.S. Dollar Amount, 1774 to Present.” Measuring Worth. Available at: http://www.measuringworth.com/uscompare. [Accessed June $18,2009]$.

Woskov PP and SK Sundaram. 2002. "Thermal return reflection method for resolving emissivity and temperature in radiometric measurements.” J. Appl. Phys. 92(10):6302-6310. 




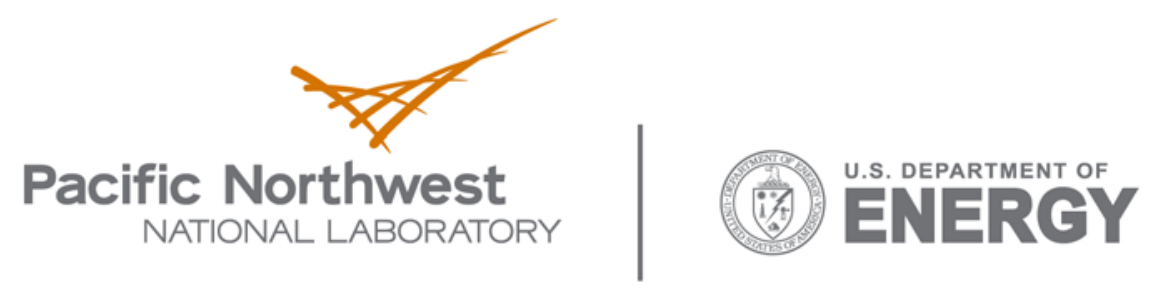

902 Battelle Boulevard

P.O. Box 999

Richland, WA 99352

1-888-375-PNNL (7665)

www.pnl.gov 